Kroneman, M., Siegers, J.J.

The effect of hospital bed reduction on the use of beds: a comparative study of 10 European

countries.

Social Science \& Medicine: 59, 2004, p. 1731-1740

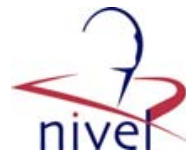

\begin{tabular}{l|l} 
Postprint Version & 1.0 \\
$\begin{array}{l}\text { Journal website } \\
\text { Pubmed link }\end{array}$ & $\underline{\text { http://www.sciencedirect.com/science/journal/02779536 }}$ \\
\hline $\begin{array}{l}\text { http://www.ncbi.nlm.nih.gov/entrez/query.fcgi?cmd=Retrieve\&db=pubmed\&dop } \\
\text { t=Abstract\&list_uids=15279929\&query_hl=67\&itool=pubmed_docsum }\end{array}$ \\
\hline$\underline{10.1016 / \text { j.socscimed.2004.01.036 }}$
\end{tabular}

* Corresponding author. Tel.:+31-30-27-2 9-640 (direct), +31-30-27-29-700 (general); fax: +3130-27 -29-729. E-mail address: m.kroneman@nivel.nl (M. Kroneman).

\title{
The effect of hospital bed reduction on the use of beds: A comparative study of 10 European countries
}

\author{
Madelon Kroneman $^{\mathrm{a}, *}$, Jacques J. Siegers ${ }^{\mathrm{b}}$

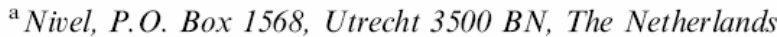 \\ ${ }^{\mathrm{b}}$ Utrecht School of Economics, Utrecht University, Vredenburg 138, Utrecht 3511 BG. The Netherlands
}

\section{ABSTRACT}

In Europe, the reduction of acute care hospital beds has been one of the measures implemented to restrict hospital expenditure. The aim of this study is to gain insight into the effect bed reductions have on the use of the remaining beds within different healthcare systems. We concentrated on two healthcare system elements:hospital financing system (per diem and global budget systems) and physician remuneration system (fee-for-service and salary systems). We also controlled for technological development and demand for healthcare. We used data from the OECD health data files of 10 North-Western European countries on hospital bed supply and use. The hospital bed indicators used were occupancy rate, average length of stay and admission rate. The data were analysed with multilevel analysis. We found some indication that the different financial incentives of hospital financing systems do indeed influence hospital bed use in the case of reductions in acute care hospital bed supply in different ways. However, we found significant effects only for the hospital bed use indicators "occupancy rate"' and "admission rate". For physician financing systems, no significant effects were found.

\section{INTRODUCTION}

In Europe in recent decades, acute care hospital bed reductions have been one of the measures used to restrict hospital expenditure (Wiley, Tomas, \& Casas, 1999; Mossialos \& Le Grand, 1999; Saltman \& Figueras, 1998). If fewer beds become available, this is likely to influence the use of the remaining beds. In this paper we will investigate the way bed reductions affect the use of remaining beds. In most of the countries concerned, governments initiated hospital bed reductions in order to contain costs in the healthcare sector. The motivation for this was often taken from Roemer's Law that reads as follows: 'A bed built is a bed filled'. Another way to contain costs was to reform the healthcare system. When governments try to reform the hospital sector they assume that interventions in the healthcare system will have an impact on hospital production. This implies that the way healthcare systems are organised affects the use of hospital 
Kroneman, M., Siegers, J.J.

The effect of hospital bed reduction on the use of beds: a comparative study of 10 European countries.

Social Science \& Medicine: 59, 2004, p. 1731-1740

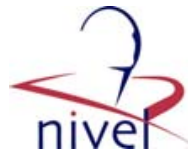

beds. The impact of bed reductions may therefore differ according to the characteristics of different healthcare systems. The aim of this study is to gain insight into the effect bed reductions have on the use of the remaining beds within different healthcare systems.

Previous research has highlighted a relationship between bed supply and bed use (Wennberg \& Gittelsohn, 1973; V.a.an.anen, H.ar . o, Vauhkonen, \& Mattila, 1967; Roemer, 1961). In particular, variations in length of stay between countries appear to depend not only on variations in case-mix, but also on factors such as hospital bed supply and the organisation of the healthcare system (Wiley et al., 1999; Westert, 1992; Van Noordt, Van der Zee, \& Groenewegen, 1992; Van Doorslaer \& Van Vliet, 1989). These findings also support the importance of including healthcare system characteristics in a study on the effect of hospital bed reductions. Most of these studies, however, deal with only one or two countries. It is not clear whether the relationship between bed supply and financing systems on the one hand and hospital bed use on the other hand is valid for all European countries.

In this study, two research questions were formulated:

(1) What is the effect of reducing acute care hospital beds on the use of remaining beds in Europe?

(2) Do differences in healthcare systems lead to differences in the effect of reducing acute care hospital beds on the use of remaining beds in Europe?

\section{STRATEGIES FOR MANAGING BED REDUCTIONS}

In this section we will discuss the strategies employed by hospital management and hospital specialists who have to deal with reductions in the hospital bed supply. In order to understand the choices of hospital and physician, we need to understand the objectives of both actors, as well as the incentives and restrictions they face. The main assignment of both hospital and physician is to improve patients' health. In the art of medicine, there is often debate about the appropriate treatment for a patient. When a type or course of treatment is uncertain, there is room for considerations other than medical interest (Mooney, 1994; McPherson, 1990; Andersen \& Mooney, 1990; Ham, 1988; Wennberg, Barnes, \& Zubkoff, 1982). We assume that hospitals strive for financial solvency and a good public image. Financial solvency is necessary for an organization to survive, and a good public image is necessary to attract patients. Evans (1984) pointed out that developing a behavioural model for the hospital is not easy, because the boundaries of what the hospital comprises may not be clear and may differ between healthcare systems, depending on who is included in the structure. The variation can range from complete vertical integration (physician, hospital as an organization and owner in one structure) to a collection of smaller firms in which physician and hospital are both firms that interact with each other. We dealt with this problem by defining the hospital management (a management team, a board of directors, for example) as the decision-maker for the hospital. The hospital management tries to achieve the goals mentioned, irrespective of the type of organization. We assume that physicians strive for a balance between a reasonable income, workload, and social approval (Delnoij, 1994; Flierman, 1991). Social approval can be acquired from peers and from satisfied patients.

The actors - hospital management and physicians — depend on each other, because the hospital provides the facilities required for patient hospitalisation, while the hospital depends on physicians for patients to fill the beds. The question of whose incentives will prevail then arises. If there is a convergence of interests, the incentives of both actors will reinforce each other. In the case of interest divergence, the question of power becomes relevant:which actor has the power to ensure that actor's incentives predominate? The formal relationship between the actors determines whose incentives prevail. In Europe, there are two types of relationship: physicians as salaried employees of the hospital, and physicians as independent entrepreneurs who hire hospital facilities. In the case of physicians who are salaried employees of the hospital, the hospital will have more formal power over them than when they are independent entrepreneurs (Burns, Andersen, \& Shortell 1989).

We will now turn to the possible strategies that can be followed when beds are reduced. Roemer's law can be interpreted as follows:all available and all new capacity will always be 
Kroneman, M., Siegers, J.J.

The effect of hospital bed reduction on the use of beds: a comparative study of 10 European countries.

Social Science \& Medicine: 59, 2004, p. 1731-1740

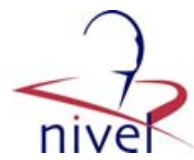

used. This implies a maximum occupancy no matter what the number of hospital beds.

However, a 100\% occupancy rate is seldom reached. According to Evans (1984), the hospital industry is at full capacity well below $100 \%$ occupancy rate. Differences in occupancy rates between countries may evolve from different institutional settings. In Europe considerable variations are found in occupancy rates*. The highest occupancy rate since 1970 is found in the Netherlands, with 89.9\% of the beds occupied in 1970. Ireland (1985), Sweden (1978) and again the Netherlands (1994) had the lowest rate, at about 70\%. Accordingly, substantial variations exist between countries and within countries. In the case of a well-developed hospital sector with a lot of beds available, bed reductions might merely be a reflection of overcapacity, originating from previous years of growth. This would contradict Roemer's law and is also not very likely because of the existing waiting list problems in most European countries (Smit \& Kroneman, 1999). Besides, variations in occupancy might reflect efficiency problems, meaning that in some healthcare systems, hospitals are at full capacity at a lower rate of occupancy than in others. Hence we arrive at a first possible strategy for managing bed reductions: increasing occupancy rates. This option has the fewest consequences for the number of hospital bed days produced. This might be achieved by reducing the share of beds kept empty for emergency cases, maintenance or cleaning, or by more efficient planning. Based on the assumption that hospitals want to maintain their service level (either because they do not want to turn away patients or because of concerns over reputation and competition (Gaynor \& Anderson, 1995)), this would be the most attractive option. However, this option is limited to a certain maximum, whatever that rate may be. Assuming that hospitals are functioning at their maximum occupancy rate despite differences between countries, then hospital bed reductions must affect the daily routine of admitting and discharging patients.

A second strategy is to reduce average length of stay, by either making use of new technologies or discharging patients at an earlier stage of recovery. A third strategy is to maintain the average length of stay and treat fewer patients, resulting in longer waiting lists or substitution by other forms of care (e.g., substitution from short-stay care to middle- or long-stay care or to ambulatory or day care). To summarise, in answering the first research question three strategies can be formulated:

In the case of reducing acute care hospital beds in a country, hospitals may react by

(a) increasing occupancy rates,

(b) reducing the average length of stay, and/or

(c) decreasing admissions.

However, the effect of the healthcare system is not yet accounted for. The preferred strategy depends on the restrictions and incentives that hospital and physician experience from the environment, such as initial bed supply, opportunities for substitution and financial incentives. The basic premise is that the actors have already adjusted their behaviour to attain an optimal situation, given the incentives their healthcare system provides. Accordingly, as a result of changing circumstances such as bed reductions, a new optimum will have to be sought. The new optimum depends also on the convergence or divergence of the interests of both actors.

Since healthcare system reforms in most countries relate to the financing system of the hospital sector, we have opted to focus on the financial restrictions of hospitals and physicians. Two hospital financing systems and their expected influence on hospital bed use will be discussed here:per diem rates and global budget systems. For each system a description will be given and the reaction to a reduction in hospital beds will be discussed. Changing conditions, such as hospital bed reductions have to lead to adaptations in behaviour. Hospital bed supply in all Western-European countries is subject to central or regional planning, and can thus be considered exogenous to individual hospitals.

In a per diem system, hospitals receive a certain amount of money for each produced bed day. This sum can be set either prospectively or retrospectively. There are no limitations on the number of bed days produced by a hospital. Per diem systems provide an incentive to keep

\footnotetext{
* The figures presented in this paragraph are from the 1998/ 1999 OECD health data files.
} 
Kroneman, M., Siegers, J.J.

The effect of hospital bed reduction on the use of beds: a comparative study of 10 European countries.

Social Science \& Medicine: 59, 2004, p. 1731-1740

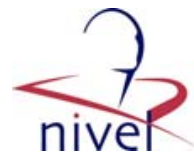

patients hospitalised as long as possible, since the later days of hospitalisation are less care intensive and therefore less costly than the first days (Barnum, Kutzin, \& Saxenian, 1995). Consequently, in a per diem system, length of stay will already be as long as possible. When bed reductions occur, we assume that these hospitals will try to affect the length of stay as little as possible. This will result in an increase in occupancy rate. If maximum occupancy is reached, a decrease in admissions will occur (fewer patients can be admitted, which may result in longer waiting lists).

A global budget system can be characterised as a system in which hospitals receive a prospective budget. In most of the countries under review, the prospective budget is related to either historical expenditure by the hospital or to demographic characteristics. Normally, budget excesses are not allowed. The global budget provides an incentive to keep the patient' s stay as short as possible, because each extra day of care will add to the costs of the hospital. The admission rate will be kept as low as possible, since the number of patients is not directive for the hospital's income (Barnum et al., 1995). In most countries the global budget is not introduced as a budget pur sang. Sometimes (as in Belgium, Denmark, Germany and the Netherlands) the global budget is also based on hospital production parameters, like number of treated patients. Overproduction or underproduction results in adjustments to the budget. For other countries (like in Germany and Belgium), overspending or underspending by the hospital may result in adjustments to the budget afterwards. However, adjustments of this kind lead to a certain range between minimum and maximum of the budget, since overspending and underspending are generally only partly compensated. Since production parameters only partly determine the financial income and not completely, as with the per diem system, we chose to treat these adjusted global budget systems together with the pure global budget systems. How will these global-budget financed hospitals react to decreasing bed supply? Whatever choice these hospitals make, it does not affect remuneration, which means other incentives may prevail. Since releasing patients earlier might result in a sicker patient population in the hospital (the first days of an admission are more care intensive than the last days) this is not a likely choice. Decreasing the number of admissions will save costs; increasing occupancy rates will not. Therefore the most probable strategy will be to reduce the number of admissions.

Besides these two systems, other financing systems are found. After WW II, open-end financing of hospitals was common (for instance, in Austria and Sweden). Hospitals could claim expenses on the basis of hospital consumption without any limits (this in contrast to the per diem system, where at least the price of one hospital bed day was fixed). Due to the growth of healthcare expenditure during the 1960s and 1970s and the wish of governments to contain healthcare costs, this system was abolished during those decades. More recently introduced systems are the diagnosis-related group system (DRG-system) and the contract-based care system. In a DRG-system, cases are classified into diagnosis and/or intervention groups. For each group a fixed payment level is settled for hospital stay, irrespective of, for instance, the actual duration (Sanderson, Anthony, \& Mountney, 1998; Barnum et al., 1995). A shorter stay is therefore more profitable. From a financial point of view, it is profitable to have as many admissions as possible with the shortest possible length of stay (Barnum et al., 1995). In a contract-based care environment, providers (hospitals) and payers (mostly third party payers) make a contract concerning the volume and conditions of hospital care. Both systems have been introduced in several countries (such as Sweden and Portugal) but neither has nationwide validity or sufficient time series; both were therefore excluded from this study. In summary, when answering the second research question the following hypothesis can be formulated:

Hypothesis 1 . In the case of reductions in acute care hospital bed supply, the preferred strategy of a hospital will be

(a) in the case of a per diem hospital financing system in a country, the occupancy rate will increase; there will be no effect on length of stay and admissions will decrease;

(b) in the case of a global budget hospital financing system in a country, occupancy rates will not rise and may even decline; length of stay will decrease, and the number of admissions will drop. 
Kroneman, M., Siegers, J.J.

The effect of hospital bed reduction on the use of beds: a comparative study of 10 European

countries.

Social Science \& Medicine: 59, 2004, p. 1731-1740

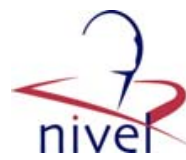

The second set of financial incentives to be discussed here is the remuneration of hospitalbased physicians. If bed reductions occur and physicians do not change the way they treat their patients (i.e. fail to alter the length of stay), fewer admissions can be carried out. For physicians paid fee-for-service, this has a direct influence on the level of their income. To maintain their income, they will have either to increase occupancy rates or shorten length of stay in order to be able to carry out as many procedures as before without changing the number of admissions. For salaried doctors, no effect is to be expected on the level of their income. They gain, however, in leisure time, since fewer services can be provided (fewer patients can be admitted where the same length of stay is maintained). Therefore, we expect fewer admissions and no change in length of stay and occupancy rates. On the basis of the expected effects of the different remuneration systems, we have formulated the following hypothesis:

Hypothesis 2. In the case of reductions in acute care hospital bed supply, the preferred strategies of physicians in different physician remuneration systems will be

(a) in the case of fee-for-service remuneration, the occupancy rates will increase, the average length of stay will decrease, and there will be no effect on the number of admissions;

(b) in the case of salaried physicians there will be no effect on occupancy rates or length of stay. The number of admissions will diminish.

Table 1 contains a schematic overview of both hypotheses.

\section{[ TABLE 1$]$}

\section{DATA AND RESEARCH DESIGN}

In order to study differences in healthcare systems, hospital data of different countries are required. In this study, the data of the 1999 OECD-healthcare database have been used. The study is limited to the North- Western European countries. The database consists of time series on acute care hospital supply and acute care hospital use from 1960 until 1995. We selected those countries with data series on bed supply and bed use for a minimum of 10 years. For Italy and Greece, in the OECD-healthcare database no sufficiently long data series were available. Consequently, these countries were excluded from the analysis. For Portugal, no data are available between 1975 and 1986. Portugal was therefore also excluded. Finland and Austria were ruled out as well. The 1999 OECD health data files for both these countries show that following a period of bed decline, there is a sudden increase of about 0.5 beds per 1000 inhabitants, after which bed reductions continue again. This more probably reflects a redefinition of hospital bed counting than a real increase in hospital beds, since in earlier versions of the OECD health data files, this sudden increase was not present. For Austria, redefinition of hospital beds is explicitly mentioned in the source information of the 1999 OECD health data files.

Since we are dealing with cross-sectional time series, a suitable method of analysis had to be found. The method had to be able to deal with country-specific regression slopes, and with autocorrelation due to the time series. A solution to this problem was found in Multilevel Analysis (Snijders \& Bosker, 1999). To identify the influence of bed supply on the use of these beds, a multilevel analysis was applied, with the yearly observation at level 1 and countries at level 2. This type of analysis permits controlling for systematic differences between countries and for time-effects (Leylan \& Groenewegen, 2003; Snijders \& Bosker, 1999). For each country, the longest possible time series of the dependent variable (either average length of stay, number of admissions per 100 inhabitants or occupancy rate) was selected for which bed capacity figures were also available. Hospital bed use can be described as a function of hospital bed supply, hospital financing system and physician remuneration system.

Since we are dealing with effects over time, all kinds of events will interfere with the expected development. Two phenomena will be discussed here:th e effect of technological advances and trends in demand for healthcare. 
Kroneman, M., Siegers, J.J.

The effect of hospital bed reduction on the use of beds: a comparative study of 10 European countries.

Social Science \& Medicine: 59, 2004, p. 1731-1740

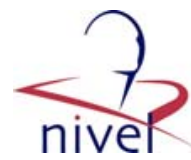

Of particular relevance is the effect of the development in medical technology. Progress in medical technology makes it possible to shorten the length of stay for certain illnesses or to perform procedures in outpatient settings. This leads to changes in average length of stays. However, technological development in the hospital sector is difficult to assess. In the OECD health data files, only large technological devices, like CT-scanners and MRI-devices are monitored. These data are available for only a few years in our total time series. The number of these devices may also be the result of regulative policy measures instead of reflecting a country's real technological advancement. Therefore, the development in medical technology was estimated by means of a proxy. Boerma, Jong, and Mulder (1993) used the number of television sets as a proxy for technological development. Based on this premise, we used the number of modern advanced electronic consumer devices per 100 inhabitants, in this case the number of television sets, personal computers and mobile phones as a proxy for technological development. Since the introduction of innovations shows an Sshape curve over time (Rogers, 1983), indicating some level of saturation, and since technological development is still progressing, we decided to include not only television sets, but also appliances that were developed later. Two practical reasons brought about the use of these data. Firstly, they were available from the World Bank Development Indicators 2001 database and, secondly, they are not likely to be subject to regulative measures by local or national governments.

The demand for healthcare is extremely difficult to estimate. In most European countries the percentage of elderly in the population is increasing. Elderly people, especially the very old, have a high risk of health problems that need long and complex treatments. The elderly have a higher clinical intervention rate compared to the younger age groups, with a peak for the 75-84 year old age group (Polder, 2001). To control for changes in demand we used the percentage of the population older than 75 as a proxy for demand for hospital care. In summary:

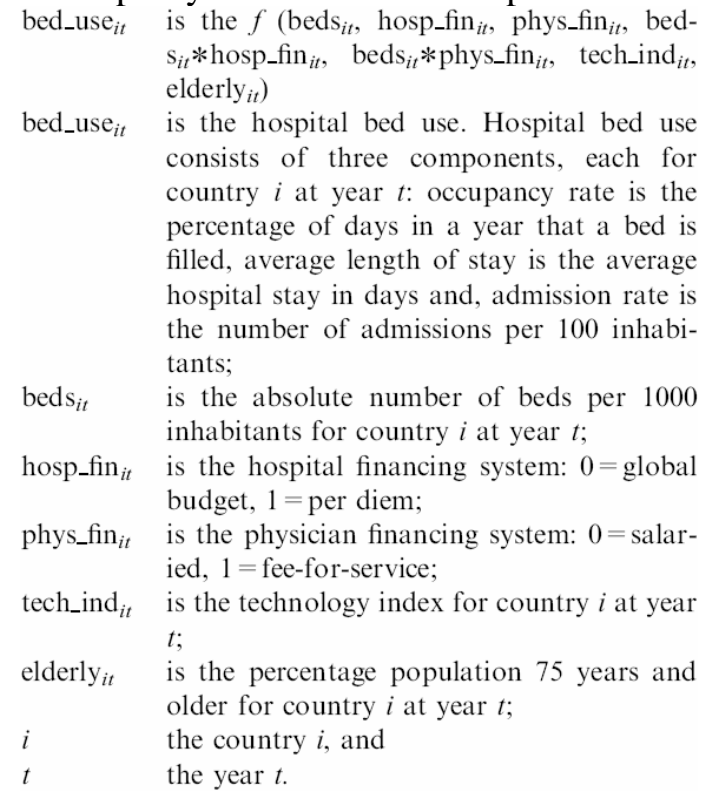

We used the MLWiN program to analyse the data (Snijders \& Bosker, 1999). We compared a full model, based on theoretical considerations, with an empty model, in which only the time component was included. The difference between both models was tested with the difference in Deviance. This difference is similar to a Chi-square distribution. The degrees of freedom are calculated by the difference in parameters between the empty and the full model.

Table 2 shows the expected signs of the coefficients, based on the hypotheses. The coefficients for beds (first row) are the coefficients in the case of a global budget system with salaried physicians. The two hypotheses (see Table 1) show that global budget systems and salaries for physicians do not have a distinct effect on occupancy rates (Table 2:column(c): occupancy rates, row (r): beds). Fewer beds in the global budget system lead to shorter stays (Table 2:c:Average length of stay, r:beds), the salary system does not influence the effect of bed reductions, hence the coefficient of beds for average length of stay is positive (Table 2:c:Average length of stay, 
Kroneman, M., Siegers, J.J.

The effect of hospital bed reduction on the use of beds: a comparative study of 10 European countries.

Social Science \& Medicine: 59, 2004, p. 1731-1740

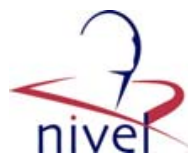

r:beds). Both the global budget system and the salary system lead to fewer admissions in the case of bed reductions, hence the coefficient of beds for admission rates is positive (c:Admission rate, r:beds). In the per diem system (r:per diem), compared to the global budget system, we expect higher occupancy rates (sign positive), longer stays (sign positive) and lower admission rates (sign negative). The per diem system (see Table 1) will, in the case of bed reduction, lead to higher occupancy rates (sign negative; r:Occupancy rate, c: beds*diem). There will be no effect on length of stay, thus the sign will be zero or negative (since the effect of the global budget system with bed reductions was positive; Table 2:c:Average length of stay, r:beds* $*$ per diem). There will be no differential effect compared to the global budget system for admission rates, thus the sign will be zero (c:Admission rates, r:beds*per diem). In the fee-for-service system (row:fee-for-service), compared to the salary system, we expect no effect on occupancy rates (sign positive), lower lengths of stay (sign negative) and higher admission rates (sign positive). For the fee-for-service system, compared to the salary system (see Table 2), hospital bed reductions will have an increasing effect on occupancy rates, thus the sign will be negative (c:Occupancy rate, r:beds $*$ fee-forservice). On length of stay, there is a decreasing effect, thus the sign will be positive (c:Average length of stay, r: beds $*$ fee-for-service) and for admission rates, there will be no effect, thus the sign will be zero or negative (since the effect of the salary system with bed reductions is positive, c:Admission rate, c:beds $*$ fee-for- service).

\section{[ TABLE 2 ]}

\section{RESULTS}

For most European countries the bed supply from 1960 to 1995 showed first an upward trend and later a downward trend (a downward trend is defined as having at least three successive years of diminishing bed supply). Roughly we can state that hospital bed policy in Western Europe has resulted in one bed less per 1000 inhabitants, every 10 years, with Sweden and Norway showing the greatest reductions and Germany the least. There is a considerable spread in the time when the hospital bed reductions started. The first countries were Sweden ('73), and the Netherlands ('75). The last country was Belgium, where bed reductions started in 1987. Hospital bed reduction is not restricted to countries with a relatively high bed supply. In the UK, which has the lowest bed supply, a considerable bed reduction is also found (see Fig. 1).

\section{[ FIGURE 1 ]}

When we look at the trend in length of stay and number of admissions, we see that the first is decreasing and the latter is increasing. We also see that these trends already existed before the introduction of bed reductions. The occupancy rate shows a rather whimsical pattern. There is no corresponding trend among the countries. To illustrate the differences among the European countries, Fig. 2 displays the trend in average length of stay for the average length of stay in Europe and the countries with the highest and lowest average length of stays.

The results of the multilevel analyses are displayed in Table 3.

\section{[ FIGURE 2 ]}

\section{[ TABLE 3 ]}

\section{Occupancy rates}

When we compare the signs of the B-coefficients in Table 3 with the expected signs in Table 2, we see that, in keeping with the expected non-significance (in the case of a global budget hospital financing system), occupancy rates are not influenced by bed supply. The expected positive sign for the per diem system was found. The physician financing system does not 
Kroneman, M., Siegers, J.J.

The effect of hospital bed reduction on the use of beds: a comparative study of 10 European countries.

Social Science \& Medicine: 59, 2004, p. 1731-1740

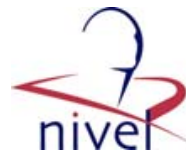

influence occupancy rates significantly, as was predicted in Table 2. The expected negative sign for the interaction effect of beds and fee-for-service appeared to be non-significant.

Countries with a larger proportion of inhabitants aged 75 years or older show higher occupancy rates. The fit of the full model improved compared to the empty model (Difference in deviance 37.36 for 7 degrees of freedom, $p<0.05$ ).

\section{Average length of stay}

Neither bed supply nor financing systems had the expected significant impact on average length of stay. The same holds for the interaction effects between financing systems and bed supply:no significant effects. The fit of the full model is not better than the empty model (deviance difference $=10.38$ for 7 degrees of freedom, $p>0.05$ ).

\section{Admission rates}

The expected positive sign for bed supply was indeed found. Admission rates appear to be sensitive to bed supply. Countries with higher bed supply show higher admission rates. The expected negative sign for the per diem system was not found, although in the per diem system an increase in bed supply is associated with a smaller increase in admission rates compared to the global budget system. There is no significant effect of physician financing system. As expected, advanced technology is associated with lower admission rates.

Our first hypothesis predicted the following:

(a) for the per diem hospital financing system an increase in occupancy rates, no effect on length of stay and decreasing admission rates, in the case of decreasing acute care hospital bed supply. We indeed found an association with an increase in occupancy rates and no effect on length of stay. However, admission rates did not drop with decreasing bed supply in the per diem system, although the increase was smaller compared to the global budget system. Accordingly, hypothesis $1 \mathrm{a}$ is partly confirmed;

(b) for the global budget system no effect on occupancy rates, decreasing lengths of stays and a drop in the number of admissions were expected in the case of hospital bed reductions. We found a significant effect on occupancy rates, in the sense that these rates decline with a decrease in hospital bed supply and there was no effect on average length of stay. The effect on admission rates was as expected, thus hypothesis $1 \mathrm{~b}$ is also partly confirmed.

The second hypothesis dealt with the effect of physician financing systems on the relationship between hospital bed supply and hospital bed use (2a and b). However, none of the predicted effects could be confirmed with the results of our analysis.

The random parts of the models show that variation among countries is higher than variation over time. Most remarkable is the decrease in variation over time.

\section{CONCLUSIONS AND DISCUSSION}

We commenced this study with the questions as to whether hospital bed reductions affect the use of the remaining acute care hospital beds and whether healthcare system characteristics influence this effect. We found some indication that the different financial incentives of hospital financing systems do indeed impact in different ways on hospital bed use, in the case of reductions in acute care hospital bed supply. However, we found significant effects only for the hospital bed use indicators "occupancy rate" and "admission rate”. It is likely that factors other than the two hospital financing systems in our study influence length of stay. We did not find different effects between fee-for-service paid physicians versus physicians in salaried service in relation to hospital bed use in the case of bed reductions. This may have to do with the position of the physician compared to hospital management. When the management of hospitals have more power, their incentives may prevail. However, further research should be undertaken to find out the effect of opposite incentives for different actors that are involved in providing healthcare. Of special interest is the increasing convergence in hospital bed use over time. Globalisation of medical action, but also of healthcare policy may contribute to this effect. Countries tend to look at their neighbours for the effect of healthcare policy making and try to copy the successful measures. This can be illustrated by the spread of the global budget system 
Kroneman, M., Siegers, J.J.

The effect of hospital bed reduction on the use of beds: a comparative study of 10 European countries.

Social Science \& Medicine: 59, 2004, p. 1731-1740

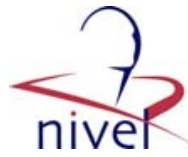

and nowadays by the spread of the introduction of market mechanisms in healthcare financing systems.

Increasing technological development was associated with decreasing admission rates. This may be explained from the rise in ambulatory surgery (Kroneman, Westert, Groenewegen, \& Delnoij, 2001). In our study, we used the adoption of advanced technological devices in the population as a proxy for hospital technological development. Although the proxy probably measures the acceptance and attitude of the population towards the use of advanced technology in a country, the actual development of hospital technology may be severely hampered by budgetary constraints and/or government regulation.

Differences in the need for hospital inpatient care were estimated by the proportion of elderly aged 75 years and older within the population. Of course, this is a very crude estimate of need, and the choice was based on availability of data. Nowadays, the concept of healthy life expectancy (HALE) as introduced by the WHO is in use. The difference between life expectancy and healthy life expectancy may be a better proxy for need. However, data on HALE is available only for recent years (World Health Organization, 2002).

This study has several additional limitations. The first limitation concerns the data from the OECD health data files. These data are unfortunately neither complete nor entirely comparable across countries. (see for instance Rublee and Schneider (1991) and Mosseveld (2003)). Is an acute care hospital bed in France the same as in Sweden in terms of the care provided to patients in such beds? This problem may be alleviated to some extent by studying the development in trends over years, as we did in this study, instead of cross-country comparison at one point in time. Moreover, efforts have been made to make the data of the OECD health data files comparable countries. Besides this, it is the only data source with extensive time series data available on European countries. Accordingly, although conclusions have to be considered with caution, we judged it worthwhile to use these data.

A second limitation concerns the time period covered: the data are rather old. More recent data are available. However, since the end of the last century, in many countries nationwide, uniform hospital and physician payment systems no longer exist. Efforts to introduce market competition produced greater variation in financial arrangements between individual hospitals and healthcare financing institutions (e.g. trust hospitals in the UK, hospital production agreements in the Netherlands). This has the effect of complicating comparisons between (international) healthcare systems, thus making the country unsuitable as a unit of analysis.

A third significant limitation is that not all relevant determinants of hospital bed use were available. There are two more important factors that influence hospital bed use. The first of these is the waiting list. A waiting list can act as a buffer, helping to manage hospital bed reductions and preventing hospital actors from changing their behaviour in the case of bed reductions. The registration of waiting lists appears to be fraught with difficulty, because of double registration in different hospitals, drop outs, and administrative problems. The latter include uncertainty over which waiting list should be recorded (waiting for the first consultation or for the procedure) and what should be registered:number of persons or length of wait. None of the countries in this study have a national, unambiguous registration of waiting lists. The second additional factor influencing hospital bed use is that day surgery and outpatient procedures can be used as a substitute for inpatient care. In that case, admissions can be reduced without influencing the service level of the population. However, there is debate in the literature, as to whether day surgery will serve as a substitute for or a supplement to inpatient care (Kroneman et al., 2001; Morgan \& Beech, 1990; Haworth \& Balarajan, 1987).

A fourth limitation is the use of proxies for technological development in the healthcare system and health care demand. The technological development in the healthcare sector may differ from technology adoption in the population due to, for instance, restrictive or stimulating financial incentives by governments or insurance companies. Healthcare demand may hopefully be estimated more accurate in the future using healthy life expectancy data. For this study, these data were not yet sufficiently available.

So far this research has analysed data at macro level. To gain further insight into the mechanisms that are used to manage bed reductions, more research should be carried out at meso or micro level. For instance in Germany, substantial hospital bed reductions are still 
Kroneman, M., Siegers, J.J.

The effect of hospital bed reduction on the use of beds: a comparative study of 10 European countries.

Social Science \& Medicine: 59, 2004, p. 1731-1740

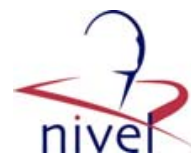

planned. In the Netherlands, too, hospital bed reductions are still taking place, mainly as a side effect of hospital mergers. An evaluation of the effects of these reductions, including alternatives for inpatient care, like day surgery and effects on waiting lists, would increase the understanding of the relationship between hospital bed supply and hospital bed use.

In conclusion, our study found some additional support for the theory that healthcare system elements - in our case hospital financing systems and hospital bed supply-influence hospital bed use (occupancy rates and admission rates). The effect of financial incentives on healthcare provider behaviour has been established previously in studies dealing with one or two countries. The results of this study imply that this is a universal effect:apparently there is room in medical decision-making for financial considerations. This finding may be of interest for healthcare policy makers, whose steering capacity in relation to the healthcare sector is mainly restricted to nonmedical decision influencing instruments. The effect of lower admission rates in the case of lower bed supply does not automatically imply a cost-saving effect or fewer patients assisted, since other types of care, like ambulatory surgery, may serve as a substitute.

\section{TABLES AND FIGURES}

Table 1

Overview of the hypotheses: The effect of bed reductions in different hospital financing systems (hypothesis 1) and physician remuneration systems (hypothesis 2)

\begin{tabular}{lllll}
\hline Hospital output parameter & \multicolumn{2}{l}{ Hospital financing system } & & \multicolumn{2}{l}{ Physician remuneration system } \\
\cline { 2 - 3 } \cline { 5 - 6 } & Per diem & Global budget & & Fee-for service \\
\hline Occupancy rate & ++ & $0(--)$ & ++ & Salary \\
Length of stay & 0 & -- & -- & 0 \\
Admission rate & -- & -- & 0 & -- \\
\hline
\end{tabular}

Table 2

Expected sign of the coefficients, based on the hypotheses

\begin{tabular}{llll}
\hline $\begin{array}{l}\text { Dependent } \\
\text { variables }\end{array}$ & $\begin{array}{l}\text { Occupancy } \\
\text { rate }\end{array}$ & $\begin{array}{l}\text { Average } \\
\text { length of stay }\end{array}$ & $\begin{array}{l}\text { Admission } \\
\text { rate }\end{array}$ \\
\hline $\begin{array}{l}\text { Independent } \\
\text { variables }\end{array}$ & & & \\
$\begin{array}{l}\text { Beds } \\
\text { Per diem }\end{array}$ & 0 & + & + \\
Beds*per diem & - & + & - \\
Fee-for-service & 0 & $-/ 0$ & 0 \\
Beds*fee-for- & - & + & + \\
service & & & $-/ 0$ \\
\hline
\end{tabular}

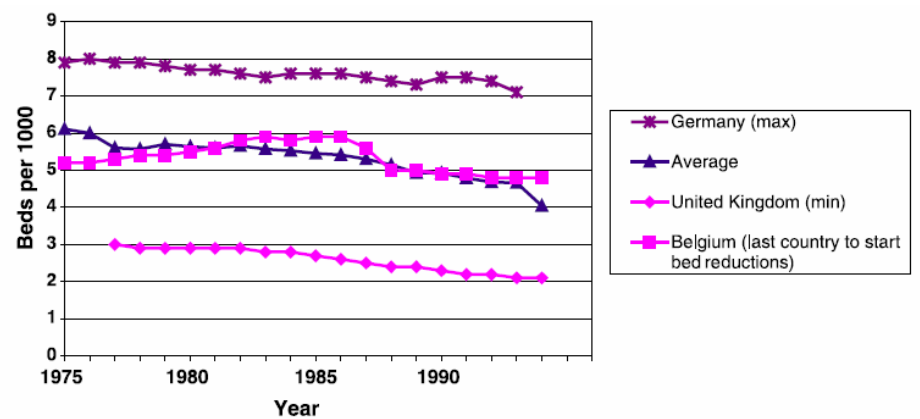

Fig. 1. Hospital bed supply in Europe from 1975 until 1994 (minimum, maximum, average and last country to start bed reductions). 
Kroneman, M., Siegers, J.J.

The effect of hospital bed reduction on the use of beds: a comparative study of 10 European countries.

Social Science \& Medicine: 59, 2004, p. 1731-1740
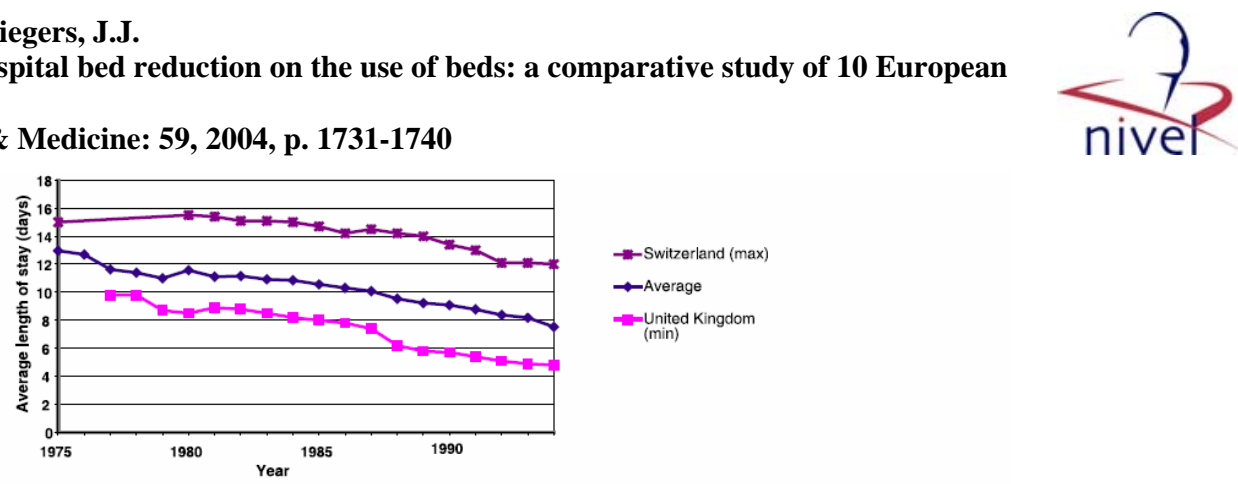

Fig. 2. Acute care hospital length of stay in Europe from 1975 until 1994 (minimum, maximum and average).

Table 3

Multilevel-analysis to explain hospital bed use

\begin{tabular}{|c|c|c|c|c|c|c|c|c|c|c|c|c|}
\hline \multirow{3}{*}{$\begin{array}{l}\text { Dependent variables }^{\mathrm{a}} \\
\text { Independent variables } \\
\text { Fixed part }\end{array}$} & \multicolumn{4}{|c|}{ Occupancy rate $(n=188)$} & \multicolumn{4}{|c|}{ Average length of stay $(n=192)$} & \multicolumn{4}{|c|}{ Admission rate $(n=192)$} \\
\hline & \multicolumn{2}{|c|}{ Empty model } & \multicolumn{2}{|c|}{ Full model } & \multicolumn{2}{|c|}{ Empty model } & \multicolumn{2}{|c|}{ Full model } & \multicolumn{2}{|c|}{ Empty model } & \multicolumn{2}{|c|}{ Full model } \\
\hline & $\mathrm{B}^{\mathrm{b}}$ & s.e. & $\mathrm{B}^{\mathrm{b}}$ & s.e. & $\mathrm{B}^{\mathrm{b}}$ & s.e. & $\mathrm{B}^{\mathrm{b}}$ & s.e. & $\mathrm{B}^{\mathrm{b}}$ & s.e. & $\mathrm{B}^{\mathrm{b}}$ & s.e. \\
\hline Beds $^{\mathrm{c}}$ & & & -0.54 & 0.67 & & & 0.16 & 0.22 & & & $\underline{1.44}$ & 0.27 \\
\hline Per diem ${ }^{\mathrm{d}}$ & & & $\underline{12.37}$ & 2.81 & & & 1.15 & 0.80 & & & $\underline{1.81}$ & 0.89 \\
\hline Beds*per diem & & & -2.06 & 0.46 & & & -0.24 & 0.13 & & & $\underline{0.32}$ & 0.15 \\
\hline Fee-for-service ${ }^{\mathrm{e}}$ & & & -2.87 & 6.48 & & & 2.98 & 2.17 & & & $-\overline{2.77}$ & 2.88 \\
\hline Beds*fee-for-service & & & 0.80 & 1.16 & & & -0.42 & 0.31 & & & -0.01 & 0.43 \\
\hline Technology index & & & 1.27 & 3.57 & & & 1.84 & 1.33 & & & -2.49 & 1.15 \\
\hline Elderly & & & $\underline{2.19}$ & 0.52 & & & -0.06 & 0.19 & & & 0.27 & 0.17 \\
\hline Year & -0.01 & 0.10 & -0.29 & 0.16 & -0.27 & 0.02 & -0.30 & 0.04 & $\underline{0.13}$ & 0.06 & $\underline{0.29}$ & 0.07 \\
\hline Constant & 79.01 & 2.80 & 74.91 & 5.58 & 16.93 & 1.01 & 16.28 & 1.87 & 11.83 & 1.78 & 0.82 & 0.20 \\
\hline $\begin{array}{l}\text { Random part } \\
\text { Level } 2\end{array}$ & (co)-var. & s.e. & (co)-var. & s.e. & (co)-var. & s.e. & (co)-var. & s.e. & (co)-var. & s.e. & (co)-var. & s.e. \\
\hline Constant & 74.75 & 36.00 & 100.38 & 47.02 & 10.40 & 4.76 & 11.57 & 5.28 & 28.42 & 12.98 & 15.62 & 7.18 \\
\hline Time & 0.11 & 0.05 & 0.12 & 0.06 & 0.00 & 0.00 & 0.00 & 0.00 & 0.04 & 0.02 & 0.03 & 0.01 \\
\hline Covar. constant $*$ time & -2.71 & 1.33 & -3.17 & 1.56 & -0.11 & 0.07 & -0.16 & 0.09 & -0.93 & 0.46 & -0.59 & 0.29 \\
\hline Level 1 & & & & & & & & & & & & \\
\hline Constant & 3.21 & 0.35 & 2.39 & 0.26 & 0.24 & 0.03 & 0.23 & 0.03 & 0.34 & 0.04 & 0.24 & 0.03 \\
\hline Deviance & & 817.46 & & 780.10 & & 357.74 & & 347.36 & & 440.89 & & 372.41 \\
\hline $\mathrm{D}_{\text {empty }}-\mathrm{D}_{\text {full }}$ & & & & ${\underline{37.36^{\mathrm{f}}}}^{\mathrm{s}}$ & & & & 10.38 & & & & $\underline{68.48^{f}}$ \\
\hline
\end{tabular}

${ }^{\mathrm{a}} n=$ number of valid observations (sum of observations for each year within each country).

${ }^{\mathrm{b}}$ Underlined B-coefficients: significant at $p<0.05$.

${ }^{\mathrm{c}}$ This is the main effect of bed supply on hospital bed use in a global budget environment with salaried physicians.

${ }^{\mathrm{d}}$ This is the additional effect of a per diem hospital financing system compared to the global budget hospital financing system.

${ }^{\mathrm{e}}$ This is the additional effect of a fee-for-service system compared to a salary system.

${ }^{\mathrm{f}}$ Significant at $p<0.05$ (Chi-square distribution with 7 degrees of freedom).

\section{REFERENCES}

Andersen, T. F., \& Mooney, G. (1990). Medical practice variations:Where are we? In T. F. Andersen, \& G. Mooney (Eds.), The challenges of medical practice variations (pp. 1-15). Hampshire:The Macmillan Press Ltd.

Barnum, H., Kutzin, J., \& Saxenian, H. (1995). Incentives and provider payment methods. International Journal of Health Planning and Management, 10, 23-45.

Boerma, W. G. W., Jong, F. A. J. M. D., \& Mulder, P. H. (1993). Health care and general practice across Europe. Utrecht:Nivel.

Burns, L. R., Andersen, R. M., \& Shortell, S. M. (1989). The impact of corporate structures on physician inclusion and participation. Medical Care, 27(10), 967-982.

Delnoij, D. M. J. (1994). Physician payment systems and cost control. Utrecht:Nivel.

Evans, R. G. (1984). Strained mercy. Toronto:Butterworth s.

Flierman, H. A. (1991). Changing the payment system of general practitioners. Utrecht:Nivel.

Gaynor, M., \& Anderson, G. F. (1995). Uncertain demand, the structure of hospital costs, and the cost of empty hospital beds. Journal of Health Economics, 14, 291-317.

Ham, C. (1988). A review of the literature. In C. Ham (Ed.), Health care variations, assessing the evidence (pp. 9-14). London:King's Fund Institute.

Haworth, E. A., \& Balarajan, R. (1987). Day surgery:Does it add to or replace inpatient surgery? British Medical Journal, 294, 133-135. 
Kroneman, M., Siegers, J.J.

The effect of hospital bed reduction on the use of beds: a comparative study of 10 European countries.

Social Science \& Medicine: 59, 2004, p. 1731-1740

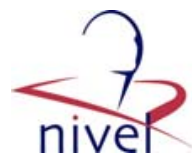

Kroneman, M., Westert, G. P., Groenewegen, P. P., \& Delnoij, D. M. J. (2001). International variations in availability and diffusion of alternatives to in-patient care in Europe:The case of day surgery. Ambulatory Surgery, 9, 147-154.

Leylan, A. H., \& Groenewegen, P. P. (2003). Multilevel modelling and public health policy. Scandinavian Journal of Public Health, 31, 267-274.

McPherson, K. (1990). Why do variations occur? In T. F. Andersen, \& G. Mooney (Eds.), The challenges of medical practice variation (pp. 16-35). Hampshire:The Macmillan Press Ltd.

Mooney, G. (1994). Key issues in health care. London: Harvester Wheatshort.

Morgan, M., \& Beech, R. (1990). Variations in lengths of stay and rates of day case surgery:Implications for the efficiency of surgical management. Journal of Epidemiology and Community Health, 44(2), 90-105.

Mosseveld, C. J. P. M. (2003). International comparison of health care expenditure, existing frameworks, innovations and data use. Voorburg, Netherlands:Statistics Netherlands.

Mossialos, E., \& Le Grand, J. (1999). Costcontainment in the EU:An overview. In E. Mossialos, \& J. Le Grand (Eds.), Health care and cost containment in the European Union (pp. 1-154). Ashgate:Aldersho t. Polder, J. J. (2001). Cost of illness in the Netherlands: Description, comparison and projection. Rotterdam:Erasmus University Rotterdam.

Roemer, M. I. (1961). Bed supply and hospital utilization:A natural experiment. Hospitals, 35(21), 36-42.

Rogers, E. M. (1983). Diffusion of innovations. London:Collier Macmillan Publishers.

Rublee, D. A., \& Schneider, M. (1991). International health spending:Compariso ns with the OECD. Health Affairs, 187-198.

Saltman, R. B., \& Figueras, J. (1998). Analyzing the evidence on European health care reforms. Health Affairs, 17(2), 85-108.

Sanderson, H., Anthony, P., \& Mountney, L. (1998). Casemix for all. Abingdon, Oxon:Radcliffe Medical Press Ltd.

Smit, R. L. C., \& Kroneman, M. (1999). Wachtlijsten in de zorg (Waiting lists for health care). In D. Post, \& L. J. Stokx (Eds.), Volksgezondheid toekomst verkenning 1997, Deel VI Zorgbehoefte en zorggebruik (pp. 119-135). Amsterdam: Elsevier/De Tijdstroom.

Snijders, T. A. B., \& Bosker, R. J. (1999). Multilevel analysis: An introduction to basic and advanced multilevel modeling. London:Sage Publications.

Väänänen, I. S., Härö, A. S., Vauhkonen, O., \& Mattila, A. (1967). The level of hospital utilization and the selection of patients in the Finnish regional hospital system. Medical Care, 5(5), 279-293.

Van Doorslaer, E. K. A., \& Van Vliet, R. C. J. (1989). 'A built bed is a filled bed?' An empirical reexamination. Social Science and Medicine, 28, 155-164.

Van Noordt, M., Van der Zee, J., \& Groenewegen, P. P. (1992). Regional variation in hospital admission rates in the Netherlands, Belgium, Northern France and Nordrhein-Westfalen. Das Gesundheidswesen, 54(4), 161-210.

Wennberg, J. E., Barnes, B. A., \& Zubkoff, M. (1982). Professional uncertainty and the problem of supplier induced demand. Social Science \& Medicine, 16, 811-824.

Wennberg, J. E., \& Gittelsohn, A. (1973). Small area variations in health care delivery. Science, 182, 1102-1108.

Westert, G. P. (1992). Variation in use of hospital care. Assen/ Maastricht:Van Gorcum.

Wiley, M. M., Tomas, R., \& Casas, M. (1999). A crossnational, casemix analysis of hospital length of stay for selected pathologies. European Journal of Public Health, 9, 86-92.

World Health Organization (2002). World health report 2002: Reducing risks, promoting healthy life. Geneva:World Health Organization. 